\title{
Janice E. Janzen: Autism Handbook for Parents: Facts and Strategies for Parenting Success
}

\author{
Prufrock Press Inc., Waco, Texas, 2009, 203 pp, ISBN: 978-1-59363-361-5, \\ $\$ 16.95$ (paper)
}

\author{
Oren Shtayermman
}

Published online: 4 February 2011

(C) Springer Science+Business Media, LLC 2011

Perhaps one of the most challenging events for parents is to be informed of their child's diagnosis of autism. Janice Janzen provides the readers with a quick reference and a wealth of information for the parents who recently learned of their child's diagnosis with an autism spectrum disorder. Although this book provides information for parents, other individuals such as educators and other family members can benefit from reading the book. Easy to read and it contains a quick reference guide which presents the important first steps that need to occur in order to assist the child on the spectrum. Much of the information presented is packaged from a teacher's perspective and the impact the diagnosis has within the education system. In particular, the glossary of terms provides a cogent way to understand some of the jargon used in academic journals and other references for parents. The current clinical and research agenda focus attention on the adolescents and young adults diagnosed with an autism spectrum disorder as well as the challenges adults face once they are no longer able to attend an educational structured system. However, the book is missing strategies to deal with the next two developmental stages of adolescents and adulthood.

The two sections of the book discussing treatment/services and educational interventions are the central reasons the book is a useful tool for parents with a school age child on the spectrum. These two sections encompass significant information that can assist in having the educational system provide the appropriate answers for the child's condition according to IDEA (Individuals with Disabilities Education Act). It suggests helpful tips along the way that can facilitate an easier process in a convoluted system. Furthermore, the author emphasizes the importance of early intervention and how critical goal settings are in relation to the child's development and progress. The author draws attention to the uniqueness of individuals on the spectrum vis-à-vis their strengths. The author refers to those strengths as "gifts." The "gifts" end the book on a positive note that hopefully provides parents the initial motivation to begin the journey of life caring for a child on the spectrum. One of the points the author is making in a covert manner is the importance of the parent's role in the facilitation of the advocacy process. As child on the spectrum will encounter challenges in domains other than academic, intervention and the strategies presented in the book are geared towards addressing issues not just at the school setting but at home and in the social environment.

O. Shtayermman $(\bowtie)$

Department of Interdisciplinary Health Sciences,

NYIT School of Health Professions, Kenneth Riland - Room

354/366, Old Westbury, NY 11568-8000, USA

e-mail: oshtayer@nyit.edu 